\title{
STUDI LITERATUR LATIHAN BERJALAN MENSTABILKAN TEKANAN DARAH PADA HIPERTENSI
}

\author{
Suharto $^{1}$, Kipa Jundapri' ${ }^{2}$, Muchti Yuda Pratama ${ }^{3}$ \\ ${ }^{1,2,3}$ Akademi Keperawatan Kesdam I/Bukit Barisan Medan, Indonesia \\ Email: hauraharto@yahoo.com ${ }^{1}$; kipa.jundapri41@ @mail.com²; \\ yudamuchti@yahoo.co.id ${ }^{3}$
}

\begin{abstract}
The risk factors of cardivasculer's diseases caused by high blood pressure. Blood pressureas uncontrolling its caused heart attack and heart failure. Walking exercise is a submaximal test whorecommended for maintenance systolic and dyastolic blood pressure for hypertension. The literature review was collecting articles from 2010-2019. Data was perfomanced by using Proquest, and Science Direct. The result of this literature review was obtained 30 articles related about walking exercise and hypertention. There was five articles who relevant with this criteria of the study. These articles used quantitative and qualitatif designs. The conclusion was walking exercise can maintenance blood pressure.
\end{abstract}

Keywords: Blood pressure, systolic dyastolic, walking exercise

\section{PENDAHULUAN}

Penyakit jantung merupakan penyakit penyebab kematian nomer satu di dunia (WHO,2017). Menurut data World Heatlh Organization (WHO) (2017) menyatakan bahwa pada 2017 populasi penderita penyakit jantung di dunia sebanyak 630.000 orang dengan 366.000 didiagnosa mengalami penyakit jantung koroner. Kasus ini diprediksi dapat meningkat sebesar $45 \%$ pada tahun 2030 (WHO, 2017). Data dari Center for Disease Control and Prevention (2017) menyatakan bahwa populasi masyarakat di dunia mengalami serangan jantung yaitu $0,5 \%$ atau sekitar 883,447 orang (CDC, 2017).
American Physical Therapy Associaton menyatakan selain faktor risiko yang tidak dapat dimodifikasi ada juga faktor risiko yang sangat berpengaruh dan akan memperburuk jantung sehingga menyebabkan serangan jantung (heart attack), seperti hipertensi menahun yang tidak terkontrol, diabetes yang menyebabkan viskositas/ kekentalan darah menjadi lebih kental mengakibatkan kerja jantung semakin berat dan tingginya kadar kolesterol dalam darah akan membentuk plak pada dinding arteri koroner sehingga terjadi penyempitan dinding arteri yang akan menghambat sirkulasi darah (Rachel et al, 2014). 
Program yang dianjurkan oleh American Heart Asossiation adalah dengan mengikuti program rehabilitasi jantung dengan melakukan latihan dengan cara komprehensif karena dilakukan oleh multidisiplin ilmu yang saling berkontribusi terhadap penyembuhan optimal fisik dan psikologis pasien jantung. Komponenkomprehensif yang terdiri dari lima komponen disiplin ilmu yang salah satunya adalah latihan fisik (exercise) yang dapat dilakukan oleh perawat (CDC, 2017). Latihan fisik (exercise) yang dimaksud adalah program latihan terstruktur yang diharapkan dapan menstabilisasi tekanan darah (PERKI, 2015). Pengaruh langsung latihan fisik terhadap jantung dan arteri koroner diantaranya adalah terhadap perbaikan fungsi endotel pembuluh darah dan perbaikan faktor risiko aterosklerosis (Giallaurian et al, 2013). Latihan fisik yang dilakukan dapat memperbaiki kapasitas fungsional, mengurangi disabilitas dan mortalitas kardiovaskular sebesar 20-26\% dibandingkan medikamentosa saja (Fitria, 2013).

\section{METODE}

Artikel yang dikumpulkan dalam studi literatur ini dikumpulkan dari tahun 2010 sampai 2019 dengan menggunakan database dari Proquest, PubMed, Medline dan Science Direct. Pengambilan sampel dalam literatur riview adalah jurnal dengan sampel pasien hipertensi, dan melakukan rehabilitasi jantung. Kata kunci yang digunakan adalah hipertensi, tekanan darah, sistolik dan diastolik. Kriteria inklusi dari artikel adalah artikel publikasi, terpublikasi 10 tahun terakhir, jurnal indonesia dan luar negeri, sedangkan disertasi, tesis, abstrak dan buku ajar menjadi kriteria eksklusi.

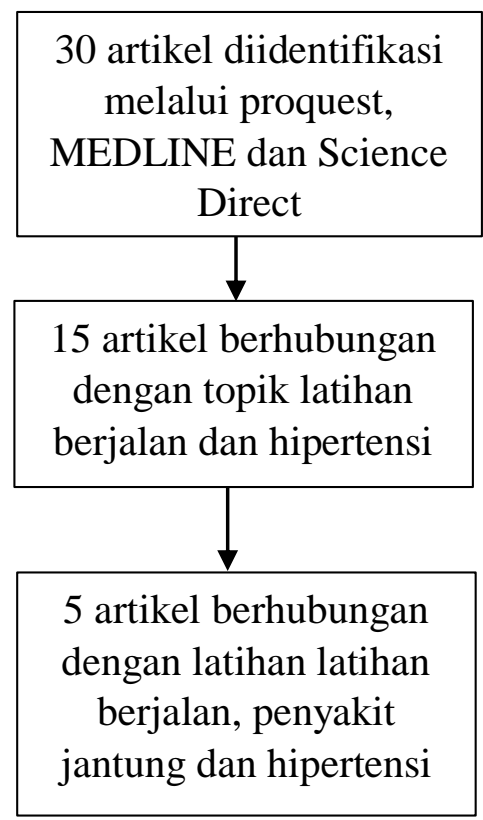

Gambar 1 Alur Proses Penyeleksian Artikel 
Tabel 1 Sintesa Hasil Penelitian Sebelumnya

\begin{tabular}{|c|c|c|c|c|c|}
\hline $\begin{array}{c}\text { Reference including: jurnal } \\
\text { title, author, volume in page } \\
\text { member }\end{array}$ & objective & $\begin{array}{c}\text { Study } \\
\text { design }\end{array}$ & Population & Results & Country \\
\hline $\begin{array}{l}\text { Effect of Exercise Training on } \\
\text { the Quality of Life and } \\
\text { Echocardiography Parameter } \\
\text { of Systolic Function in } \\
\text { Patients With Chronic } \\
\text { Hypertension } \\
\text { Ali Hassanpour Dehkordi, } \\
\text { Asian J. Sport Med.2015 } \\
\text { March;6(1);e22643 }\end{array}$ & $\begin{array}{l}\text { Penelitian ini } \\
\text { untuk } \\
\text { menginvestigasi } \\
\text { efek dari } \\
\text { exercise dalam } \\
\text { ejection } \\
\text { fraction pada } \\
\text { pasien } \\
\text { hipertensi }\end{array}$ & $\begin{array}{l}\text { Quasi } \\
\text { experiment }\end{array}$ & $\begin{array}{l}66 \text { orang } \\
\text { dengan } 33 \\
\text { kelompok } \\
\text { intervensi } \\
\text { dan } 33 \\
\text { kelompok } \\
\text { kontrol }\end{array}$ & $\begin{array}{l}\text { Hasil penelitian } \\
\text { mengindikasi } \\
\text { bahwa program } \\
\text { exercise punya } \\
\text { efek signifikan } \\
\text { terhadap skor } \\
\text { kualitas hidup. } \\
\text { Ada perbedaan } \\
\text { signifikan skor } \\
\text { kualitas hidup } \\
\text { pada grup } \\
\text { intervensi } \\
\text { sebelum } \\
\text { program dan } \\
\text { setelah program } \\
\text { (p } \leq 0.05 \text { ). }\end{array}$ & Iran \\
\hline $\begin{array}{l}\text { Effect of 8-week exercise- } \\
\text { based cardiac rehabilitation } \\
\text { on Cardiac Autonomic } \\
\text { Funtion }\end{array}$ & $\begin{array}{l}\text { Meneliti apakah } \\
\text { ada efek dari } \\
\text { rehabilitasi } \\
\text { jantung: } \\
\text { walking (latihan }\end{array}$ & $\begin{array}{l}\text { Quasi } \\
\text { Experiment }\end{array}$ & $\begin{array}{l}45 \\
\text { Intervensi } \\
\text { grup dan } \\
45 \text { control } \\
\text { grup }\end{array}$ & $\begin{array}{l}\text { Latihan yang } \\
\text { diberikan } \\
\text { memberikan } \\
\text { efek } \\
\text { menurunkan }\end{array}$ & USA \\
\hline $\begin{array}{l}\text { Oliveira et,al (2014). } \\
\text { Research Center in Pysical } \\
\text { Activity Journal. } \\
\text { Doi:10.1016/j.ahj.2014.02.001 }\end{array}$ & $\begin{array}{l}\text { dasar pada } \\
\text { pasien jantung) } \\
\text { yang } \\
\text { mengalami } \\
\text { hipertensi } \\
\text { terhadap fungsi } \\
\text { otonom jantung }\end{array}$ & & & $\begin{array}{l}\text { HRV yang } \\
\text { menunjukksn } \\
\text { bahwa jantung } \\
\text { mampu } \\
\text { mengkompensasi } \\
\text { latihan dengan } \\
\text { menurunkan } \\
\text { Heart Rate. }\end{array}$ & \\
\hline $\begin{array}{l}\text { The effects of baseline heart } \\
\text { rate recovery normality and } \\
\text { exercise training protocol on } \\
\text { heart rate recovery in patient } \\
\text { with hypentension and heart } \\
\text { failure }\end{array}$ & $\begin{array}{l}\text { Menguji } \\
\text { pengaruh faktor } \\
\text { protokol } \\
\text { exercise } \\
\text { training dan } \\
\text { dasar } \\
\text { normalitas }\end{array}$ & $\begin{array}{l}\text { Quasi } \\
\text { experiment }\end{array}$ & $\begin{array}{l}\text { kontrol } 16 \\
\text { orang, dan } \\
\text { kelompok } \\
\text { intervensi } \\
16 \text { orang }\end{array}$ & $\begin{array}{l}\text { Ada peningkatan } \\
\text { HHR2 terhadap } \\
\text { HHR1 setelah } \\
\text { latihan pada } \\
\text { kelompok } \\
\text { intervensi dan } \\
\text { kelompok }\end{array}$ & Turkey \\
\hline $\begin{array}{l}\text { Yalin Tolga Yaylah, Guilin } \\
\text { Finfikoglu, } \\
\text { Anatol J Cardiol 2015:15:727- } \\
34\end{array}$ & $\begin{array}{l}\text { HHR dalam } \\
\text { mengubah HRR } \\
\text { pada HF }\end{array}$ & & & kontrol. & \\
\hline
\end{tabular}


Lanjutan Tabel 1

\begin{tabular}{|c|c|c|c|c|c|}
\hline $\begin{array}{c}\text { Reference including: } \\
\text { jurnal title, author, volume } \\
\text { in page member }\end{array}$ & objective & $\begin{array}{l}\text { Study } \\
\text { design }\end{array}$ & Population & results & Country \\
\hline $\begin{array}{l}\text { Maximizing Patient Benefit } \\
\text { From } \\
\text { Cardiac Resynchronization } \\
\text { Therapy With hypertension } \\
\text { to } \\
\text { the Addition of Structured } \\
\text { Exercise Training } \\
\text { Ashish Y. Patwala, MB } \\
\text { CHB, Paul R. Woods, } \\
\text { Journal of the American } \\
\text { College of Cardiology Vol. } \\
53\end{array}$ & $\begin{array}{l}\text { Pengaruh program } \\
\text { exercise training } \\
\text { terstruktur selain } \\
\text { CRT(Cardiac } \\
\text { Resynchronization } \\
\text { Therapy) dalam } \\
\text { memaksimalkan } \\
\text { perbaikan } \\
\text { kapasitas latihan, } \\
\text { gejala, dan } \\
\text { kualitas hidup } \\
\text { (QOL) }\end{array}$ & $\begin{array}{l}\text { Quasi } \\
\text { experiment }\end{array}$ & $\begin{array}{l}\text { Populasi } \\
50 \text { orang. } \\
\text { Kontrol } 25 \\
\text { orang dan } \\
\text { intervensi } \\
25 \text { orang }\end{array}$ & $\begin{array}{l}\text { Exercise } \\
\text { training } \\
\text { mengarah pada } \\
\text { perbaikan lebih } \\
\text { lanjut dalam } \\
\text { kapasitas } \\
\text { latihan, } \\
\text { hemodinamik, } \\
\text { dan QOL. Oleh } \\
\text { karena itu, } \\
\text { latihan olahraga } \\
\text { memungkinkan } \\
\text { manfaat } \\
\text { maksimal yang } \\
\text { harus dicapai } \\
\text { setelah } \\
\text { CRT }\end{array}$ & $\begin{array}{l}\text { United } \\
\text { Kingdom }\end{array}$ \\
\hline $\begin{array}{l}\text { Effect of a 6-month } \\
\text { pedometer-based } \\
\text { walking intervention on } \\
\text { functional capacity } \\
\text { in patients with } \\
\text { hyperntension and chronic } \\
\text { heart failure } \\
\text { with reduced (HFrEF) and } \\
\text { with preserved } \\
\text { (HFpEF) ejection fraction: } \\
\text { study protocol for two } \\
\text { Multicenter randomized } \\
\text { controlled trials. } \\
\text { Tomas Vetrovsky, Michal } \\
\text { Siranec, Jiri Parenica, ett.all } \\
\text { Vetrovsky et al. J Transl } \\
\text { Med (2017) 15:153 }\end{array}$ & $\begin{array}{l}\text { Mengevaluasi } \\
\text { intervensi berjalan } \\
\text { berbasis } \\
\text { pedometer } \\
\text { terhadap nilai } \\
\text { fraksi ejeksi }\end{array}$ & $\mathrm{RCT}$ & $\begin{array}{l}\text { Populasi } \\
200 \text { orang, } \\
100 \\
\text { perlakuan } \\
100 \\
\text { kontrol }\end{array}$ & $\begin{array}{l}\text { Menggunakan } \\
\text { pedometer } \\
\text { latihan } \\
\text { memberikan } \\
\text { umpan balik } \\
\text { yang cukup bagi } \\
\text { pasien untuk } \\
\text { mematuhi } \\
\text { program tanpa } \\
\text { pengawasan } \\
\text { Program latihan } \\
\text { yang intens } \\
\text { seperti } \\
\text { olah raga dan } \\
\text { aktivitas fisik } \\
\text { sebagai bagian } \\
\text { integral } \\
\text { manajemen } \\
\text { gagal jantung, } \\
\text { dan } \\
\text { memperbaiki } \\
\text { kesehatan pasien } \\
\text { gagal jantung }\end{array}$ & Prague \\
\hline
\end{tabular}

HASIL

Hasil penelusuran elektronik yang dilakukan, ditemukan 30 artikel, yang ungan dengan penyakit jantung. Artikel tersebut dianalisa dan didapatkan hanya 5 artikel yang memenuhi kriteria inklusi dan berhubungan dengan latihan berhubungan dengan latihan berjalan dan 18 artikel berhub

berjalan, tekanan darah (sistol dan diastol) dan hipertensi. Artikel yang ditemukan berupa penelitian kualitatif dan kuantitatif. Hasil penelusuran 
menemukan faktor risiko terjadinya hipertensi di masyarakat.

\section{PEMBAHASAN}

Penyakit jantung salah satunya adalah hipertensi yang merupakan penyakit yang disebabkan beberapa faktor yang dapat dimodifikasi dan tidak dapat dimodifikasi (ACSM, 2014). Faktor yang dapat dimodifikasi seperti menghindari asap rokok, olah raga teratur, menjaga asupan nutrisi garam tidak berlebihan, dan mengatur pola tidur yang baik dan penyakit terdahulu seperti hipertensi (Fitria, 2013).

\section{Hipertensi}

Tekanan darah merupakan faktor penting dalam sistem peredaran darah dan indikator penting dari aktivitas jantung. Tekanan darah merupakan cerminan dari resistensi perifer, jika tekanan darah meningkat, maka hal tersebut mencerminkan adanya peningkatan resitensi perifer dan hal ini menjadi tanda bahwa jantung mengalami peningkatan afterload. Afterload meningkat, maka kebutuhan dari miokard terhadap oksigen juga akan meningkat (Fitria, 2013). Hipertensi yang tidak terkontrol dan tidak dikombinasi dengan perbaikan gaya hidup akan memperburuk keadaan miokard jantung sehingga jantung tidak mampu untuk mengkompensasi kebutuhan miokard terhadap oksigen (ACSM, 2014).

$$
\text { Giallauria et al. (2013) }
$$
menyatakan bahwa gaya hidup yang tidak baik seperti merokok, pengaturan diet yang tidak tepat pada hipertensi, diabetes dan kolesteromia, serta kurangnya aktivitas fisik seperti berolahraga merupakan faktor yang paling sering menyebabkan heart attack (serangan jantung) dan merupakan penyebab angka perawatan rumah sakit yang tinggi. Pengaturan diet yang tepat serta dibarengi dengan olah raga teratur adalah cara untuk menstabilkan tekanan darah (ACSM, 2017). American Health Association merekomendasikan olahraga yang sangat mudah dilakukan oleh penderita penyakit jantung adalah dengan latihan berjalan.

\section{Latihan Berjalan}

Latihan berjalan adalah latihan submaksimal yang dapat diukur dengan jarak (mets) yang dilakukan diatas permukaan datar selama 30 menit. Latihan ini merupakan latihan yang direkomendasi oleh American Heart Association (AHA) untuk penyakit jantung. Penyakit jantung bukan menjadi kendala pasien dalam melakukan latihan berjalan asalkan pasien sudah dianggap 
mampu untuk melakukan latihan.

Sebelum latihan, pasien harus memiliki hemodinamik yang stabil sehingga latihan akan mempercepat kompensasi tubuh. Latihan ini tidak hanya membawa manfaat bagi pasien untuk mempercepat proses penyembuhan pasien dengan mencapai pemenuhan kebutuhan pasien secara mandiri seperti makan, mandi, dan segala aktivitas sehari-hari yang sudah direkomendasikan dapat dilakukan oleh pasien jantung (ACSM, 2014).

Berbagai penelitian menunjukkan adanya hasil yang signifikan terhadap beberapa parameter seperti denyut nadi recoverydan hemodinamik jantung non invasif setelah pemberian berbagai program exercise (latihan) dan dilakukan pada beberapa jenis penyakit seperti penyakit obstruksi paru dan gagal jantung (Pozehl, 2014). Hasil penelitian Dehkordi (2015) menunjukkan bahwa latihan berjalan memiliki hasil yang signifikan $(\mathrm{p}<0.05)$ pada pasien gagal jantung terhadap peningkatan kualitas hidup (Dehkordi el al, 2017).

Makris et al., (2012) menyatakan bahwa program latihan yang disupervisi mampu mengurangi komplikasi dari penyakit periperal arteri disease (PAD) yang dinilai dari peningkatan kapasitas fungsional dan kualitas hidup. Hasil penelitian Yaylah (2015) menunjukkan bahwa latihan berjalan memberikan efek dalam proses pemulihan yang diukur dengan heart rate recovery pada pasien gagal jantung. Sedangkan pada penelitian Mustika (2013) latihan berjalan menunjukkan peningkatan nilai fraksi ejeksi dengan nilai signifikan $(\mathrm{p}<0,001)$ pada pasien pasca intervensi koroner percutan (Markis et al, 2012).

Yin-Shu et al., (2015) didapatkan bahwa latihan berjalan dapat memberikan efek postitif terhadap fungsi autonomi jantung pada pasien gagal jantung yang diukur dengan heart rate recovery dan heart rate variability. Penelitian yang dilakukan oleh Myers et al (2007) dengan melakukan supervisi latihan jalan hospital-based satu jam berjalan dengan 45 menit bersepeda statis sebanyak 5 kali seminggu selama 8 minggu mampu memperbaiki heart rate recovery ( $\mathrm{Yu}$ el al, 2007). Hasil penelitian yang dilakukan oleh Giallauria (2013) didapatkan hasil bahwa program latihan berjalan setelah fase akut myocardiac infarct dapat mengurangi stres hipoperfusi dan dapat meningkatkan fungsi ventrikel kiri yang ditunjukkan dengan nilai $\mathrm{p}<0.01$ (Giallauria et al, 2013). 


\section{KESIMPULAN}

Kesimpulan dalam pembahasan literatur riview adalah latihan berjalan berpengaruh terhadap stabilisasi tekanan darah. Tekanan darah yang terkontrol akan mencegah terjadinya serangan jantung. Latihan berjalan yang dianjurkan adalah latihan dengan jalan di area datar selama 30 menit.

\section{SARAN}

Penderita hipertensi dapat menjaga tekanan darah agar selalu stabil dengan melakukan latihan berjalan setiap hari minimal 1 kali sehari, selama 15 - 30 menit. Selain itu juga menghindari stres dan rajin mengontrol tekanan darah.

\section{Daftar Pustaka}

ACSM's (American College of Sports Medicine. (2014). Resource Manual for Guiedlines for Exercise Testing and Prescription. Lippincott.

Budiman \& Sihombing, R. (2015). Hubungan Dislipidemia, Hipertensi dan Diabetes dengan Angka Kejadian Infark Miokard Akut. Cimahi. Retrieved from http://jurnal.fkm.unand.ac.id

CDC (Center for Disease Control and Prevention). (2017). Center for Disease Control and Prevention. Retrieved from http://cdc.ac.id.

Colins, C. T,. \& Lunos, S, (2011).Effect of a Home-BasedWalking Intervention on Mobility and Quality of People with Diabetes and
Peripheral Arterial Diseases. USA Journal of Medicine.

Dehkordi, A. H., \& Far, A. K. (2017). Effect of Exercise Training on the Quality of Life and Echocardiography Parameter of Systolic Function in Patients With Chronic Heart Failure: a Randomized Trial.Asian J Sport Med. 6(1);e22643.

Dianna, Z., \& Herlambang, K.. Analisis Faktor Risiko Kejadian Penyakit Jantung Koroner di RSUD Karidi Semarang. Semarang.2013. Retrieved from http://stikes.karidi.com.

Fitria, W. (2013). Pengaruh Frekuensi Latihan Fisik Terhadap Peningkatan HHR Pada Pasien Post CABG. Jakarta.

Giallauria, F., Acampa, W., Ricci, F., Vitelli, A., Torella, G., Lucci, R., Del Prete, G., Zampella, E., Assante, R., Rengo, G., Leosco, D., Cuocola, A., Vigorito, C. (2013). Exercise Training Early after Acute Myocardial Infraction Reduces Stress-Induced Hyperfusion and Improves Left Ventrivular Function.Eur J Nucl Med Imaging, 40.. 315-324.

Halimuddin. (2016). Tekanan Darah dengan Kejadian Infark Pasien ACS. Retrieved from http://ideanursingjournal

Infodatin. (2017). Pusat Data dan Informasi Kementerian Kesehatan RI. Jakarta

Kocur, P., Smielecka, E.D., Wilk, M., Dylewicz, P. (2009).Effect of Nordic Walking on Exercise Capacity and Fitness in Men 
Participating in Early, Short-Term Inpatient Cardiac Rehabilitation after an Acute Coronary Syndrome.Clinical Rehabilitation 23:995-1004.

Lemaitre, J.P., Harris, S., Keith, A.A. Denvir, M. (2004).Change in Circulating Cytokines After 2 Forms of Exercise Training in Chronic Stable Heart Failure. Elsevier Journal.

Luo, N., Merril, P., Parikh, K., Whellan, D., Pina, I.L., Fiuzat, M., Kraus, W.E., Kitzman, D.W, Keteyian, S.J., Ments, R.J. (2017). Exercise Training in Patient With Chronic Heart Failure and Atrial Fibrilation. Journal of the American of Cardiology.

Markis, G.C., Lattimer, C.R., Lavida, A., Geroulakos, G. (2012). Availability of Supervised Exercise Program and the Role of Structured Home-based Exercise in Peripheral Arterial Disease.European Journal of Vascular and Endovascular Surgery, 44. 569-575.

Oliveira, N. L., Ribeiro, F., Teixeira, M., Campos, L., Alves, A.J., Silva, G., Oliveira, J., Aveiro, P., Gaia, V.N. (2014).Effect of 8-Week ExerciseBased Cardiac Rehabilitation on Cardiac Autonomic Function: A Randomized Controlled Trial in Myocardial Infraction Patients.Research Center in Physical Activity Journal.

Papathanasiou, J.V., Ilieva, E.M., Nikolov, F.P. (2012).Exercise Training Modes in Rehabilitation of Patients With Chronic Heart
Failure. Folia Medica Journal, 54:4.

Patwala, Y. A., Woods, P.R., Sharp, L., Goldspink, D. F., Wright, D.J. (2009). Maximing Patient Benefit From Cardiac Resynchronization Therapy with the Addition of Structured Exercise Training.Journal of the American College of Cardiology. 53:2.

PERKI (Perhimpunan Dokter Spesialis Kardiovaskuler Indonesia). (2015).Pedoman Tatalaksana Sindrom Koroner Akut edisi ketiga. Jakarta.

Posehl, B., \& Duncan. (2014). Study of Adherence to Exercise in $H F$. USA. BMC Cardiovaskular Disorder 2014, 14:172

Rachael, L., Hytros, M., Gedamkar, G., Farrell, A.V., Thomas, E. (2014). Guidelines fot the Six Minutes Walk Test. American Thoracic Society.

R. Brake., Jones, ID. (2017). Chronic Heart Failure Part 2: Treatment and Management. European Heart Journal 24:1014.

Reeves, G. R., Whellan, D.J. Duncan, P., Pastva, A.M., Eggebeen, J.D., Hewston, L.A., Morgan, T.M., Reed, S. D., Rejeski, W.J., Kitzman, D.W. (2017).Rehabilitation Therpy in Older Acute Heart Failure Patients (REHAB-HF) Trial: Design and Rationale. Elsevier Journal.

Schulz, O., Kromer, A., Iiebenstein, B., Berlin. (2002).Cardiac Troponin I: A Potential Marker of Exercise Intolerance in Patient With 
Moderate

Heart

Failure.Interventional Cardiology

Berlin Spandau. 2-8703.

Stromberg. A., Martensson, J., Fridlund.

B., Levin, L-A., Karisson, J.E., Dahlstrom. (2003).Nurse-Led

Heart Failure Clinics Improve Survival and Self Care Behavior in Patient with Heart Failure. European Heart Journal 24. 10141023.

Suharsono, $\mathrm{T}, . \quad \& \quad$ Yetti, K,. (2013).Dampak Home Based Exercise Training Terhadap Kapasitas Fungsional Pasien Gagal Jantung Di RSUD Ngudi Waluyo Wlingi. Malang. Retrived from www.ebso.co.id

Sutrisno, J. (2011). Hubungan Kebiasaan Posisi Tidur Dengan Risiko Terjadinya Serangan Ulang Pasien Penyakit Jantung Koroner di Poli Jantung RSUD Gambiran Kota Kediri. Kediri. Retrieved fromhttp://www.portalgaruda.com Vanzelli, A. S., Medeiros, A., Rolim, N., Bartholomeu, J.B., Cunha, F.T., Bechara, G.L., Gomes, E.R.R., Mattos, K.C., Sirvente, R., Salemi, V., Mady, C., Negrao, C.E., Guastimosim, S., Brum, P.C. (2013). Integrative Effect of Carvedilol and Aerobic Exercise Training Therapies on Improving Cardiac Contractility and Remodeling in Heart Failure Mice. Plos one 8(5): e62452.

Vetrovsky, T., Siranec, M., Parenica, J., Griva, M., Stastny, J., Precek, J., Pelouch, R., Bunc, V., Linhart, A., Belohlavek, J. (2017). Effect of a 6Month Pedometer-Based Walking
Intervention of Functional Capacity in Patient with Chronic Heart Failure with Reduced (HFrEF) and with Preserved (HFpEF) Ejection Fraction: Study Protocol for Two Multicenter Randomized Controlled Trials.Journal of Translation Medicine. 15:153.

WHO (World Health Organization). (2017). Heart Disease and Prevention. Retrived from http://who.gov.ac.id

Yu. S.F., Lee. D. T.F., Jean, W., Hui, E. (2007). NonPharmacologicalIntervention in Older People with Heart Failure: Effects of Exercise Training and RelaxationTherapy. Geron-tology Clinical Section. . 53:74-81. 